\title{
GODROADS: Modalities of
}

\section{Conversion in India. Editors: Peter}

\section{Berger, Sarbeswar Sahoo}

Edition 4, 2020

Matthew Wilkinson

DOI: 10.37839/MAR2652-550X4.26

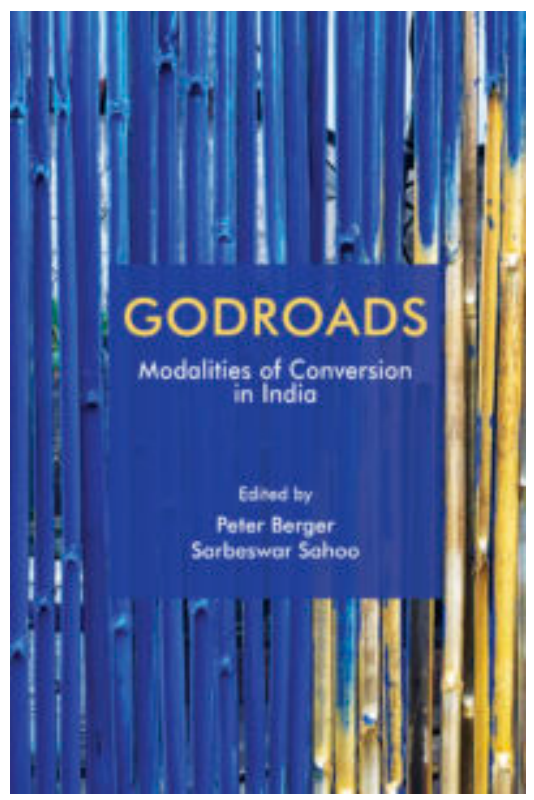

Discussions of conversion in India generally focus on Christianity, most often imagining conversion to be an unambiguous transition from polytheistic Hindu or animist faiths to the British coloniser's monotheistic and 'superior' faith. This is a narrative that is rife with colonial and social Darwinist undertones, one that endorses a narrow and limiting understanding of conversion as a distinct event. GODROADS: Modalities of Conversion in India challenges these limitations.

Through twelve chapters, 10 of which explore distinct case studies of conversion, GODROADS explores the multifaceted and multidirectional nature of conversion in 
India. The book offers an alternative script for the Indian conversion experience, one that conceptualises conversion as a heterogenous experience and examines the implications of conversion not just for the individual, but for communities and for greater social structures and processes. Ultimately, GODROADS presents conversion as an ongoing process and not a singular transformational event. This process involves movement in various directions back and forth as converts selectively embrace, resist, and interpret their adoptive religions to suit their own distinct needs and local context.

GODROADS employs roads as a recurring motif to understand the conversion experience and to capture the complexity of the phenomenon of conversion. As Editors Peter Berger and Sarbeswar Sahoo discuss in the Introduction, roads are connected to religion in manifold ways, and not only in the sense that religions offer certain paths to salvation-roads are sites of reflection, a moral geography in relation to which the loss of traditions and moral anomie can be contemplated. In this way, roads are liminal spaces. Berger and Sahoo aptly describe this perspective early on, arguing that 'like travelling on a road, the process of conversion can be fast or slow, there may be obstacles on the way, a street may turn out to be a dead end, and even if this is not the case, one may decide to turn around and return to where one started (but perhaps revisiting later)'.

The Introduction is followed by 10 empirical chapters each discussing a distinct aspect of conversion in India. These chapters employ various methodologies, from archival historiographies to ethnographic fieldwork, to discuss the multifaceted aspects of the conversion experience. For example, Fernande W. Pool's Chapter 3, Religious Conversion as Ethical Transformation draws on long-term ethnographic fieldwork to examine reformism in the anthropology of conversion in Joygram, West Bengal, demonstrating that conversion is part of a larger process of social renewal and moral regeneration attached to local ideas of personhood and to the context itself. In Chapter 4, Conversion versus Unity, Frank Heidemann probes archival records of early Badaga conversions on the Nilgiri Hills of south India, demonstrating that the narratives of Christian conversion were informed by a 
Brahminical view on Hinduism following a master narrative of Brahmin conversion to Christianity. Iliyana Angelova draws on a career of ethnographic fieldwork with the Sumi Naga (one of the major ethnic groups in Nagaland), in Chapter 5, Identity Change and the Construction of Difference, arguing that a combination of utilitarian and intellectual motivation underpins religious transformation among the Sumi, acting simultaneously to encourage a reconstruction of Naga identity as Christian throughout the Naga independence struggle.

Throughout the book's empirical chapters, an overarching theme of conversion as defined by the individual and attached to myriad local dynamics is made apparent. In Chapter 9, Reservation and Religious Freedom, Saberswar Sahoo unpacks the increasing incidents of Hindu-Christian conflict in Odissa and Rajasthan. Sahoo asks why Christians have been increasingly targeted recently, as compared to the early $20^{\text {th }}$ century where Hindu-Christian conflict was very rare. Sahoo argues that rising Hindu-Christian violence is related to changing caste relationships and tensions surrounding freedom of religion. The final empirical chapter, Peter Berger's Rupture and Resilience, explores the complex overlaps between Gadaba and Hindu religions in Highland Odisha and the ways understandings of deities, the politics of diet, and alcohol consumption intersect in a community hosting a number of conversion events. Berger's chapter offers an insight into the back-and-forth nature of the conversion experience, and the ways conversion involves selective adoption of old and new religious traditions.

GODROADS empirical chapters are followed by Aoeracuda Vukaca's Afterword, offering insights into India's conversion experience from the perspective of an Amazonia specialist and highlighting the ways that conversion is better understood as a complex and ongoing process rather than a moment of rupture and distinct transformation.

Ultimately, GODROADS is faced with the complication of understanding and conceptualising religion in a context of diverse and complex religious traditions, where even the most secular and political processes take on a religious idiom. This 
makes understanding conversion in India, and in some ways understanding the concept of conversion itself, extremely challenging. Overall, GODROADS responds to this challenge well, offering a thorough discussion and analysis of the conversion experience in India from diverse perspectives while also recognising the localised, subjective and individual nature of the conversion experience. GODROADS offers a valuable addition to literature on religion in India and on the wider conversion experience.

Banner image: Praying hands, India. Credit: Adam Cohn/Flickr 